\title{
Ecos de Quintana na poesia contemporânea gaúcha
}

Marcelo Spalding *

\begin{abstract}
Resumo: Por ocasião do centenário de Quintana fui convidado a escrever uma reportagem para o Jornal da Universidade sobre a influência de Mario Quintana nos poetas gaúchos contemporâneos. Foram entrevistados oito poetas, todos radicados em Porto Alegre, e suas respostas foram muito semelhantes: sete dos oito havia lido toda obra de Quintana e o relia esporadicamente, mas nenhum soube apontar como essa leitura havia influenciado na sua obra, tampouco apontar essa influência em algum dos seus pares. $\mathrm{O}$ presente trabalho parte das respostas destes poetas para analisar as semelhanças de três poemas: "Os degraus", de Mario Quintana, e dois poemas sem título, um de Fabrício Carpinejar e outro de Paula Taitelbaum, ambos publicados em livros do século XXI por poetas porto-alegrenses da novíssima geração. Se não poderemos concluir, devido a pequena amostra, que Mario Quintana é decisivo para os novos poetas, também não poderemos deixar de sentir nessa comparação ecos de Quintana na poesia contemporânea.
\end{abstract}

Palavras-chave: Mario Quintana, Fabrício Carpinejar, Paula Taitelbaum, poesia contemporânea, poesia porto-alegrense

\begin{abstract}
On the occasion of Mario Quintana's centennial, I was invited to write a report for the University Journal about the influence of Mario Quintana on contemporary poets from the Brazilian state of Rio Grande do Sul. Eight poets were interviewed, all of them living in Porto Alegre, and their answers were very similar: seven out of eight individuals had read all of Quintana's works and would re-read them every now and then, but none of these poets was able to point out how such a reading had influenced their own work, nor could they point out such an influence in any of their peers. The present paper sets off from the answers given by these poets so as to analyse the similarities among three poems: 'Os Degraus' by Mario Quintana, and two untitled poems, one by Fabrício Carpinejar and another one by Paula Taitelbaum, both published in $21^{\text {st }}$ century books by brand-new generation Porto Alegre poets. If we, due to the reduced number of samples, cannot come to the conclusion that Mário Quintana is decisive for the new poets, we also may not forget to feel in such a comparison some echoes of Quintana in contemporary poetry.
\end{abstract}

Keywords: Mario Quintana, Fabrício Carpinejar, Paula Taitelbaum, contemporary poetry, poetry from Porto Alegre

Poucos escritores confundem-se de tal maneira com a história de uma cidade, poucos poetas representam com tamanha fidelidade o seu ofício, poucos homens transformam-se em personagem e projetam sua existência além-morte com tanto sucesso. É o caso de Mario Quintana.

Poeta que dispensa apresentações, Quintana é da "família poética da chamada segunda geração [modernista], que brotou nos anos 1930, pela ênfase no lirismo, pela liberdade de praticar o soneto e sem pedir licença escrever poemas-piada e poemas em prosa" (FISCHER

\footnotetext{
* Marcelo Spalding é graduado em Jornalismo pela Universidade Federal do Rio Grande do Sul e mestrando em Literatura Brasileira na mesma Instituição.
} 
\& FISCHER, 2006). Não alcançou, entretanto, a dimensão nacional imediata de um Carlos Drummond de Andrade, um Vinícius de Moraes ou uma Cecília Meireles, mas o tempo correu a seu favor, e depois de ter se consolidado como nome obrigatório das letras gaúchas, apenas comparado a Érico Veríssimo, tem sido reconhecido como expoente da poesia nacional pelos acadêmicos e goza de grande popularidade mesmo depois de sua morte.

A poesia de Mario Quintana, como já notaram vários "quintanólogos", tem uma grande penetração popular. A prova estatística disso é o sucesso de venda alcançado pelos seus livros, em especial a antologia Os cem melhores poemas de Mario Quintana, que se encontra entre as mais vendidas da coleção Os Melhores Poemas, organizada pela Global. A comprovação empírica dessa popularidade está no fato de Quintana ter "caído na boca do povo". É a colegial que escreve no caderno de lembranças da colega: "Uma vida não basta apenas ser vivida: também precisa ser sonhada". É o advogado que vive a disparar: "O futuro é uma espécie de Banco, ao qual vamos remetendo, um por um, os cheques de nossas esperanças. Ora! Não é possível que todos os cheques sejam sem fundos". São os alunos de Letras que andam com uma camiseta do curso ostentando os dizeres: "Fere de leve a frase... E esquece... Nada / Convém que se repita... / Só em linguagem amorosa agrada / A mesma coisa cem mil vezes dita". (YOKOZAWA, 2006, p. 68)

Sintomático dessa popularidade é o Decreto número 43.810, de 24 de maio de 2005, do Governo do Estado do Rio Grande do Sul, que instituí o ano de 2006 como o "Ano do Centenário de Mario Quintana", abrindo caminho para uma série de atividades que movimentou a mídia e a população gaúcha numa clara demonstração de vitalidade da obra do poeta.

É natural, diante disso, que escritores das gerações seguintes a Quintana, pelo menos aqueles nascidos na cidade que de tal forma se confunde com o poeta, Porto Alegre, tenham alguma influência deste, hipótese que serve de ponto de partida para este ensaio. Nossa pesquisa começou, na verdade, como busca de material para uma reportagem em que deveria se levantar o legado de Quintana ${ }^{1}$. Na ocasião, foram entrevistados alguns poetas portoalegrenses contemporâneos - Ricardo Silvestrin, José Eduardo Degrazia, Amir Feijó, Sérgio Napp, Mario Pirata, Paula Taitelbaum, Jaime Vaz Brasil, Ronald Augusto e, posterior à publicação da reportagem, Fabrício Carpinejar - e se questionou se haviam lido, e ainda reliam, a obra do poeta. Após esta questão, perguntamos se de alguma forma Mario Quintana os havia influenciado, e se sentiam essa influência na poesia de outros poetas da atualidade.

Os oito poetas responderam que leram a obra de Quintana, e sete dos oito afirmaram reler esporadicamente suas poesias, mas quase todos têm dificuldade de encontrar essa influência em seu trabalho. Ricardo Silvestrin afirma que sua obra se construiu e se constrói também a partir de tudo o que lê, mas "não há um traço especifico, e sim um diálogo criativo com a tradição literária”. José Eduardo Degrazia vê pouca influência direta de Quintana em

\footnotetext{
${ }^{1}$ SPALDING, Marcelo. A imortalidade de Mario Quintana. Jornal da Universidade, Porto Alegre, n. 90, p. 13, agosto de 2006. As citações dos poetas aqui reproduzidas sem referência estão publicadas nesta reportagem
} 
sua poesia, "mas a maneira de ver o cotidiano por um lado meio fantástico, o domínio do soneto de uma forma mais moderna, tudo isso me interessou e me interessa muito". Amir Feijó - que assim como Degrazia chegou a conviver pessoalmente com o poeta - também vê semelhança na forma de tratar o cotidiano, "as alegrias e dissabores dos momentos insossos da realidade". Respostas semelhantes dão Jaime Vaz Brasil, que se diz envaidecido por um crítico ter-lhe apontado "ecos de Quintana”, mas não reconhece nem rejeita tais traços; Sérgio Napp, que se diz inicialmente influenciado por Drummond, mas relendo sua obra, descobre "traços do Mário"; e Mario Pirata, que lembra o poeta mesmo na forma de negar a semelhança: "o anjo do Mario tinha as asas na bunda e voava em círculos; o meu, bundão e bobalhão, voa em círculos ao redor de suas próprias asas".

Ronald Augusto é o único que nega qualquer traço, afirmando ter sido Manuel Bandeira quem o jogou para a poesia. E é Paula Taitelbaum, em sua resposta, quem sem querer dá uma pista do porquê dessa dificuldade dos contemporâneos em encontrar traços de Quintana em suas poesias: "todos os verdadeiros poetas se parecem de algum modo, sempre buscando dizer muito através do pouco, sempre tentando criar uma imagem e uma fantasia, sempre tateando o mundo através das mãos da emoção", e conclui que "não deixamos de ser um pouco da soma dos poetas que amamos, e eu realmente amo a voz de Quintana, mas seria arrogante da minha parte dizer que minha obra tem algum traço dele. Se alguém tem que dizer isso, não sou eu".

A situação de constrangimento e indecisão se acentua quando os poetas são convidados a apontar colegas seus que trouxessem mais marcada essa influência de Quintana. Amir Feijó lembra "Armindo Trevisan, Walmir Ayala, com seus versos maravilhosos para crianças, Gláucia de Souza, Maria Dinorah, as ótimas poesias infantis de Carlos Urbim, Ferreira Gullar, Celso Gutfreind e Ana Maria Machado”. Jaime Vaz Brasil, ainda dizendo que "vai demorar algumas gerações para surgir algum poeta com a obra e o carisma de Quintana", aponta Luiz Coronel como seu herdeiro natural. Degrazia pensa em "Paulo Hecker Filho, mas ele era contemporâneo de Quintana". E o próprio Degrazia arremata com uma frase que poderia ser pronunciada por todos os outros entrevistados: "no meu entender ninguém tem a pretensão ou quer ser influência de Quintana porque ele era único, uma voz particular cantando o mundo à sua maneira".

Fabrício Carpinejar (2006), que chegou a ser comparado a Mario Quintana pela crítica nacional, não destoa da opinião de seus colegas: reconhece influência, mas sorri quando fazem comparações: 
Já ouvi comparações, mas quem sai perdendo é o Quintana. O poeta me influenciou pela duplicidade e ambigüidade de seus poemas. Aquele ar antigo de acomodação e suspiro, o diminutivo cheirando a elogio, as reticências inacabando os versos... Tudo aparência para o leitor chegar perto e descobrir uma meditação violenta sobre a ordem das relações familiares. (Email)

Esta dificuldade de identificar influência de forma clara parece ser inerente ao trabalho de qualquer poeta. O próprio Quintana, questionado em certa entrevista de 1989 sobre suas influências, afirmou que "não há propriamente influência literária de um autor na gente, há confluência. [...] Este pessoal [é que] tem mania de descobrir influências na gente. Imagina que chegam a dizer que as obras de Shakespeare não foram escritas por ele!" (VERISSIMO, 2006, Online).

Indo além da pesquisa jornalística, suficiente apenas para a reportagem, cabe de fato ao pesquisador aceitar a provocação de Paula e procurar a "voz de Quintana" na poesia - e não só na palavra - dos poetas contemporâneos. Mas é evidente que aceitar tal provocação e procurar influências definitivas de Quintana na obra destes e outros poetas é tarefa hercúlea e requer uma vida, ou pelo menos uma tese, não sendo, neste momento, nosso objetivo. Mas a partir da leitura da poesia de dois destes poetas, Fabrício Carpinejar e a própria Paula Taitelbaum, procuramos traços que indicassem uma semelhança, ou melhor, um eco, algo que não ocorre de forma totalmente proposital, tampouco está sempre presente, mas faz-se sentir a partir de uma análise mais profunda.

Esta comparação, por limitações de espaço, será feita a partir de três poemas: "Os Degraus", de Mario Quintana, publicado originalmente em Baú de Espantos, livro de 1986 em que "há poemas de grande tristeza, quem sabe pela velhice que se instalara, mas sempre com aquela verve que o caracterizara (FISCHER; FISCHER, 2006, p. 78), e dois poemas sem título, um de Fabrício Carpinejar e outro de Paula Taitelbaum. Antes de os reproduzir vale a pena ressaltar que tanto o poema de Fabrício como o de Paula foram publicados em livros do século XXI (ela em O mundo da lua, de 2002; ele em Livro de visitas, de 2005) por poetas porto-alegrenses nascidos na viragem dos sessenta para os setenta (1969, ela; 1972, ele) e que estrearam na literatura em 1998 (Eu versos eu, ela; As solas do sol, ele), ou seja, depois da morte de Mario Quintana.

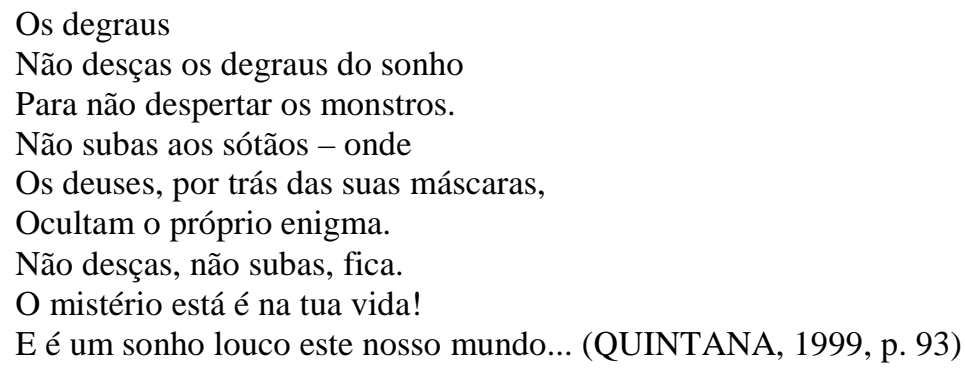




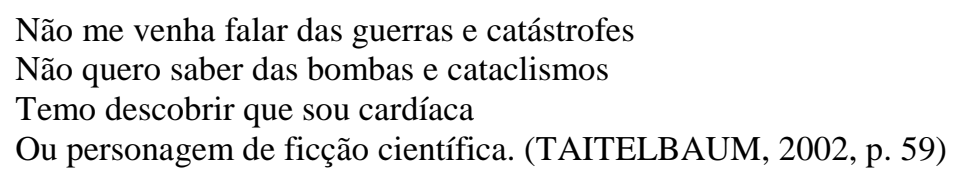

Não quero ter escolhas para escolher errado.

Sou o que não será cobrado.

Meu armário é a mala entreaberta. (CARPINEJAR, 2005, p. 93)

Em um primeiro olhar percebemos a construção em versos livres e a brevíssima extensão dos poemas, características que os contemporâneos têm não apenas adotado como acentuado em relação aos modernistas (sintomático, neste sentido, o fato de o poema de Quintana ter oito versos e os demais, quatro e três). Em todos eles o verbo projeta uma ação futura, na verdade uma negação - inclusive os três começando com "não" - seguido em dois deles por um verbo no imperativo, e no terceiro por um verbo em primeira pessoa que também indica, se não uma ordem, um pedido para o interlocutor.

Esse pedido é, na verdade, uma rejeição ao livre arbítrio moderno, livre arbítrio que exige do sujeito decisões constantes sem dar-lhe certeza dos caminhos a seguir: "O deus, dono do pensamento uno, tem a liberdade de desprezar-nos e de apiedar-se de nós por causa dessa dualidade, cuja responsabilidade nos atribui” (BLANCHOT, 2001, p. 139). Aquilo que para toda uma geração foi uma grande conquista, o poder de escolha, tornar-se-ia nas mãos do sujeito contemporâneo e descrente uma responsabilidade demasiada e até perigosa.

O primeiro verso de Carpinejar, "não quero ter escolhas para escolher errado", torna-se assim a síntese dos três poemas. É no fundo o que representam também as imagens "não desças, não subas" e "não me venha falar": a preferência pela ignorância. Ou o temor pela cobrança do que está errado, que desestabiliza o sujeito a ponto de ele não ter sequer um armário, leia-se um lar. Armário e mala, desta forma, funcionam como metomínias cotidianas para a existência.

O uso de termos cotidianos na construção de metáforas poéticas é uma característica marcante de Quintana e também dos dois autores contemporâneos escolhidos. Mario já dizia que "as idéias andam pelo ar e pousam na cabeça da gente [...] como passarinhos" (VERÍSIMO, 2006, Online), concepção que contribui para o tom coloquial e cotidiano de seus versos. Mas também nos dois poemas contemporâneos aqui reproduzidos temos imagens cotidianas como cardíaca, armário, mala (bem como em Quintana tínhamos degraus, sótãos). Talvez no poema de Paula Taitelbaun essa idéia de cotidiano esteja mais ligada à coloquialidade, mas em outros poemas de sua obra, bem como na de Carpinejar, veremos que 
o dia-a-dia é uma constância. Em reportagem, a Revista Entre Livros chegou a comparar Fabrício Carpinejar com Quintana, exatamente neste ponto: "Caso raro de poeta que imprime lirismo popular sem ser piegas, Carpinejar lembra seu conterrâneo Mario Quintana - o que talvez indique o futuro de sua recepção crítica" (PINTO, 2005, p. 31).

Já Paula Taitelbaum inicia o poema com elementos universais e hiperbólicos como guerras, catástrofes, bombas, cataclismos, para encerrá-lo com um termo destoante, "personagem de ficção científica", dando leveza e ao mesmo tempo profundidade aos versos. Ao criar uma figura tão ingênua e tão própria da cultura de massas contemporânea: “a personagem de ficção científica", o sujeito poético assume sua alienação atual e reforça o pedido para que não o tirem dela, não venham falar de questões cruciais, bombas, guerras.

Bombas e guerras é também o que deve haver além dos degraus de Quintana, onde acima ou abaixo do lugar do sujeito poético vivem deuses mascarados ocultando o grave enigma da existência, enigma feito não para ser decifrado, mas ignorado. Por isso não subas, não desças, fica. Imobilize-se, aliene-se, também sugerem os sujeitos poéticos de Carpinejar e Paula Taitelbaum. Feche-se em sua própria vida, afinal nosso mundo nada mais é do que um "sonho louco".

Evidentemente é preciso ver nessa postura alienada e alienante dos sujeitos poéticos uma ironia fina da posição do sujeito perante as dificuldades, perante as graves questões contemporâneas. Uma ironia sem rancor, nada cáustica, uma ironia à Quintana, a quem o termo mais adequado seria humour:

Mais do que pelo fato de propor uma separação entre as duas categorias críticas, a diferença estabelecida por Quintana e outros escritores interessa aqui na medida em que revela uma preocupação ética e estética desses artistas: todos eles lembrados como ironistas, fazem questão de observar, em última instância, que não são indiferentes ao seu objeto de derrisão; [...] destino que os obriga a se voltarem ironicamente sobre o seu mundo, com o qual não lhes é possível estar em estado de graça, de fusão, e a sofrerem com isso, uma vez que amam o mundo por eles ridicularizado. (YOKOZAWA, 2006, p. 96)

Assim, tanto a opção do sujeito de Paula Taitelbaum quanto o de Fabrício Carpinejar pela alienação é uma forma de conviver com o mundo que amam, este mundo ridículo: por causa das bombas, guerras, e mesmo das malas entreabertas, assim como a opção dos poetas pelo humor é a sua forma de conviver neste "sonho louco".

Em outra direção, mas com ponto de chegada semelhante, podemos ver o humor como fuga do sentimentalismo. Quintana afirmou, na entrevista supracitada de 1989, que "o meu humor, também nos meus poemas, é uma coisa para disfarçar o sentimentalismo. A gente tem pudor de ser sentimental, de ser muito romântico, então recorre ao humor” (VERISSIMO, 
2006, Online). Desta forma pode-se ler "Os Degraus" como o lamento de uma desilusão, e o poema de Carpinejar como a proximidade de mais uma desilusão amorosa.

Ao humor, os compêndios de literatura brasileira costumam associar uma fina melancolia como característica fundamental da obra de Quintana (PICCHIO, 2004, P. 567; BOSI, 1997, p. 463), melancolia esta sentida de forma evidente nos versos aqui reproduzidos dos contemporâneos.

Em Carpinejar, toda carga melancólica é lançada ao final, com a imagem da mala entreaberta simbolizando mais uma relação, possivelmente amorosa, desfeita, e sugerindo que essa seja uma sucessão na vida do sujeito poético, deixando transparecer uma melancolia que perpassa toda a obra de onde retiramos este poema: "Na poesia de Carpinejar, o rancor comedido das pequenas coisas perpassa lembranças [...] Mais: na poesia de Carpinejar, surpreende-se o sentimento do perdão que não foi obtido, o companheirismo que foi negado, a solidariedade que chegou tarde, a perda que não é aceita" (GONÇALVES, 2005, Online). Já em Paula Taitelbaum a melancolia é a fusão do ponto de partida catastrófico com o final quase infantil, lúdico, capaz de tirar o peso dos primeiros versos e deixar no leitor uma leve sensação de desajustamento do mundo.

Verdade que estas semelhanças apontadas não são suficientes para se falar numa influência clara, nem mesmo esse tom melancólico e irônico é próprio dos poetas contemporâneos gaúchos. Calvino já associava melancolia e ironia à leveza, um dos valores do terceiro milênio (em que Fabrício Carpinejar e Paula Taitelbaum escrevem): “Assim como a melancolia é a tristeza que se tornou leve, o humor é o cômico que perdeu o peso corpóreo e põe em dúvida o eu e o mundo, com toda a rede de relações que os constituem" (CALVINO, 1990, p. 32).

Também a sensação de desajustamento do sujeito pós-moderno no mundo contemporâneo é tema recorrente na literatura, pelo menos desde o modernismo, quando o tema fundamental passou a ser a crise de unidade do sujeito (REIS, 2003, p. 458). Tal crise é potencializada ao longo do século XX que culmina no que Jameson (1996) chama de vazio pós-moderno: “é isso então, num sentido amplo, o que é pós-moderno em Simon: o vazio evidente do sujeito, para além de toda fenomenologia, sua capacidade de adotar um outro estilo como se fosse um outro mundo" (p. 151).

Sendo assim é preciso ponderar, antes de falarmos em influências ou traços, que as questões suscitada por Quintana em “Os degraus" são perfeitamente alinhadas a contemporaneidade. Porém, não parece difícil encontrar na obra da geração leitora e admiradora do poeta, como aqui tentamos demonstrar, ecos de sua estética e temática. A 
coloquialidade das palavras, a leveza das imagens, o cotidiano dos conflitos, a melancolia das sugestões, a liberdade do verso, o desajustamento do sujeito: traços modernos trabalhados por Quintana de tal forma que o tornaram dono de uma poesia pessoalíssima e de difícil caracterização. Poesia que é fonte inesgotável, na qual parece inevitável irem seus conterrâneos mais jovens beber, originando daí uma produção interessante e ainda não estudada de poemas a Quintana (não confundir com os inúmeros poemas para Quintana).

\section{Referências}

BLANCHOT, Mauricio. A conversa infinita. São Paulo: Escuta, 2001.

BOSI, Alfredo. História concisa da Literatura Brasileira. 42.ed. São Paulo: Cultrix, 1994.

CALVINO, Ítalo. Seis propostas para o próximo milênio. São Paulo: Companhia das Letras, 1990.

CARPINEJAR, Fabrício. Livro de Visitas. Rio de Janeiro: Bertrand Brasil, 2005. de 2006.

Quintana. Mensagem recebida por: marcelo@marcelospalding.com em 19 de jul.

FISCHER, Luís Augusto; FISCHER, Sérgio Luís. Mario Quintana: uma vida para a poesia. Porto Alegre: WS Editor, 2006.

GONÇALVES, Adelto. O rancor das pequenas coisas. In: Fabrício Carpinejar, setembro de 2005. Disponível no endereço da WEB <http://www.carpinejar.com.br/critica.htm>. Acessado em 26/09/2006.

GOLDSTEIN, Norma. Versos, sons, ritmos. São Paulo: Ática, 1999.

JAMESON, Fredric. Pós-Modernismo: a lógica cultural do capitalismo tardio. São Paulo: Editora Ática, 1996.

PINTO, Manuel da Costa. Um esboço do futuro cânone brasileiro. Revista EntreLivros, São Paulo, n. 5, p. 28-34, setembro de 2005.

QUINTANA, Mario. Antologia poética. Porto Alegre: L\&PM, 1999.

REIS, Carlos. O conhecimento da literatura: introdução aos estudos literários. Porto Alegre: EDIPUCRS, 2003

SPALDING, Marcelo. A imortalidade de Mario Quintana. Jornal da Universidade, Porto Alegre, n. 90, p. 13, ago. de 2006. 
STEGAGNO-PICCHIO, Luciana. História da Literatura Brasileira. 2.ed. Rio de Janeiro: Nova Aguilar, 2004.

TAITELBAUM, Paula. O mundo da lua. Porto Alegre: L\&PM, 2002.

VERISSIMO, Fernanda. Homenagem a Mario Quintana (entrevista). In: Terra Magazine, agosto de 2006. Disponível no endereço da WEB <http://terramagazine.terra.com.br/interna/0,,OI1090046-EI6595,00.html>. Acessado em 25/09/2006.

YOKOZAWA, Solange Fiuza Cardoso. A memória lírica de Mario Quintana. Porto Alegre: UFRGS, 2006. 